\title{
fTELLE \\ Ritual Mapimaí - A Festa de Criação do Mundo dos Paiter Suruí
}

\author{
Mapimai Ritual-The party of the world Creation of the Paiter \\ Surui
}

\section{Mapimaí Ritual - La fiesta de la creación del mundo de los Paiter Surui}

Luis Carlos Maretto

Universidade Federal de Rondônia

lcmaretto@gmail.com

\author{
Almir Narayamoga Suruí \\ Universidade Federal de Rondônia \\ almirsurui@gmail.com \\ Adnilson de Almeida Silva \\ Universidade Federal de Rondônia \\ adnilsonn@gmail.com
}

\begin{abstract}
Resumo
O presente artigo retrata a cultura dos Paiter Suruí, especificamente sobre sua realidade e a origem de seu universo, que é reproduzida em representações festivas e ritualísticas que mantém viva sua identidade. Dentre os vários rituais existentes, o Mapimaí explica a origem do mundo. Os símbolos representativos do Mapimaí em 2011, objeto desta pesquisa, foram o gavião real, a floresta e o rio. O grupo Kaban, dono da chicha e anfitrião do evento, conduziu o ritual e escolheu a aldeia Apoena Meireles, localizada em Rondolândia, Mato Grosso, para ser o lócus de sua representação. A ritualística é realizada com a bebida chicha que pode ser feita de mandioca, cara, milho ou inhame. Uma pintura é feita num tronco de madeira (trono) em que os convidados pelo dono da chicha vão se sentar. Finalizados todos os preparativos, os grupos Gamep, Gamir, Makor e Kaban se encontram e desafiam entre si a beber chicha até não suportar mais. Os casais dançam em círculo de mãos dadas ou abraçados sob o som de flauta e cantos cujas letras abordam o papel do gavião real, da floresta e do rio - como elementos de construção da identidade - e as letras não se repetem. Em suma, a intenção do evento ritualístico é o fortalecimento da união entre os Paiter Suruí.
\end{abstract}

Palavras-chave: Paiter Suruí; Ritual Mapimaí; Representações Indígenas. 


\begin{abstract}
The following article depicts the Paiter Suruís culture, and specifically their reality and the origin of their universe that is reproduced in festive and ritualistic representations which keep their identity alive. Among the several existing rituals, the Mapimai explains the origin of the world. In 2011, the representative symbols of the Mapimai - object of this research - were the royal hawk, the forest and the river. The group called kaban which owns the chicha and hosts the event, held the ritual and chose the Apoena Meireles village located in Rondolandia, Mato Grosso, to be the locus of its representation. The ritual is performed using the chicha drink which can be made out of cassava, corn or yam. A painting is done on a wooden trunk (throne) on which the guests of the chicha owner will get seated. After all the preparations, the groups called Gamep, Gamir, Makor and Kaban meet and challenge each other to drink the chicha until they cannot bear it anymore. Couples dance in a circle either holding hands or hugging each other following the sound of the flute and chants whose songs' lyrics shed light on the role of the royal hawk, the forest and the river, as the identity's constructive elements. The lyrics are never repeated. In short, the aim of the ritualistic event is to strengthen the unity between the Paiter Suruí.
\end{abstract}

Key Words: Paiter Suruí, Mapimaí Ritual, Indigenous representations.

\begin{abstract}
Resumen
Este artículo describe la cultura de los Paiter Suruí, especialmente su realidad y el origen de su universo, que se reproduce en las representaciones festivas y rituales que mantienen su identidad viva. Entre los varios rituales existentes, el Mapimaí explica el origen del mundo. En 2011, los símbolos que representaron el ritual del Mapimaíobjeto de esta investigación- fueron el halcón real, el bosque y el río. El grupo Kaban que posee la chicha y es el anfitrión del evento, llevó el ritual a cabo y eligió el pueblo Apoena Meireles situado en Rondolândia, Mato Grosso, para ser el lugar de su representación. El ritual se realiza con la bebida llamada chicha que puede ser hecha de yuca, maíz o papa. Se hace una pintura en un tronco de madera (trono) en el qual los invitados del propietario de la chicha podrán sentarse. Hechos todos los preparativos, los grupos Gamep, Gamir, Makor y Kaban, se encuentran y desafían unos a los otros a tomar chicha hasta que no logran soportar más. Las parejas bailan en un círculo tomados de la mano o abrazados, con el sonido de la flauta y cantos cuya letra aborda el papel del halcón real, la selva y el río - como componentes de la construcción de la identidad. Las letras no se repiten. En breve, la intención del evento ritual es el fortalecimiento de la unión entre los Paiter-Suruí.
\end{abstract}

Palabras clave: Paiter Surui; El ritual del Mapimaí; Representaciones indígenas.

\title{
Introdução
}

O artigo apresenta o ritual festivo Mapimaí, realizado pelos Paiter Suruí ou Paiterey (forma como se referem coletivamente a si mesmos), por meio de um evento tradicional que praticam como parte de sua representação de mundo. A prática reflete a importância cultural como agrupamento humano e cujos desdobramentos consolidam o modo de vida deste povo em seu cotidiano.

O trabalho teve origem em agosto de 2011, quando a equipe composta por pesquisadores do Programa de Pós-Graduação Mestrado em Geografia da Universidade Federal de Rondônia foi convidada pelos Paiterey a visitar a Terra Indígena Sete de Setembro (autodenominada Paiterey Garah), especificamente a 
Aldeia Apoena Meireles, localizada em Rondolândia, Estado do Mato Grosso, e participar do ritual Mapimaí.

O objetivo traçado pela equipe consistiu em levantar os elementos de estudo, dados, informações e recursos, os quais auxiliam na parte descritiva e na construção do presente trabalho. Os subsídios levantados permitem a modelagem da pesquisa e oferecem ao leitor a essência, o espírito e o aspecto mítico do ritual.

O trabalho de pesquisa é justificado devido ao acesso a um importante acervo cultural dos Paiterey, os quais mantém viva sua cultura e utilizam o ritual como forma de representação, ou seja, um forte instrumento de manifestação de sua identidade étnica.

Em termos históricos, os Paiter Suruí de Rondônia foram contatados oficialmente em 1969, falam a língua Tupi do tronco Mondé. Sua autodenominação significa "Gente de Verdade" e constituem-se nos seguintes clãs exogâmicos $^{1}$ patrilineares': Gamep, Gamir, Makor e Kaban. Vivem na Terra Indígena Paiterey Garah ou Sete de Setembro (nome dado pela sociedade envolvente) na divisa entre os Estados de Rondônia e Mato Grosso, com uma população aproximada de 1.350 pessoas (ISA, 2012).

Em seu ritual de representação admitem não indígenas convidados pelo dono da chich $^{3}$. No ano de 2011, este ritual foi organizado e oferecido pelos Kaban, como os "donos da chicha", na aldeia Apoena Meireles, e foram eleitos como símbolos para representar este cerimonial a floresta, o rio e o gavião real (Harpia harpyja), cujo alvo é o macaco prego (Cebus sp.). A escolha varia de clã para clã e conforme as circunstâncias vigentes do momento.

Nas etapas do ritual do Mapimaí foram abordadas várias passagens como: o Íwai (roça), Metare (floresta), o Iamá (banco de madeira ou trono de sabedoria), enfeites corporais, fabricação de flautas, pintura corporal, entrada pela noite, o casamento, o pagamento pela festa, a preparação da roça, a caça e distribuição de alimentos. Todas estas etapas e passagens encontram-se descritas no desenvolvimento deste trabalho de pesquisa.

\section{Os Paiter Suruí e a Terra Indígena Sete de Setembro}

Os Paiterey foram contatados oficialmente em sete de setembro de 1969 pela FUNAI, e se organizam em clãs exogâmicos e patrilineares que são: Gamep

\footnotetext{
${ }^{1}$ Exogâmicos: Praticam a união ou casamento de membros de diferentes grupos étnico-raciais.

${ }^{2}$ Patrilineares: Fundamenta na descendência paterna. O parentesco, a herança, o sobrenome e a autoridade são transmitidos do pai para os filhos.

${ }^{3}$ Chicha (Bebida fermentada preparada a base de mandioca ou milho, cará, inhame, batata, amendoim etc.

Quanto mais fermentada maior o teor alcoólico)
} 
(marimbondos pretos), Gamir (marimbondos amarelos), Makor (taboca) e Kaban (mirindiba ${ }^{4}$ azeda) (ISA, 2012).

A etnia tem uma governança regida pelo Parlamento Suruí, o qual é composto pelo Pamatot Ey, Labiway Ey e o Labiway Esaga, os quais representam os clãs. Atualmente o Parlamento é regido por uma carta de princípios e aspirações, criada em novembro de $2010^{5}$.

Na visão do Instituto Sócio Ambiental o Parlamento Suruí tem o seguinte significado para este povo:

[...] é uma instância de debates democráticos de ideias, reflexões e deliberações, representa o povo Paiter Suruí em suas decisões, reivindicações, implantação de políticas internas e na interface com as políticas públicas governamentais. Rege-se por uma organização hierárquica, formada pelo PAMATOT EY (Conselho dos Anciãosinstância superior de sabedoria), $L A B I W A Y E Y$ (parlamentares eleitos pela população a cada período de 05 anos) e LABIWAY ESAGA (líder maior do Povo Paiter Suruí) (ISA, 2012).

Os Paiterey habitam 25 aldeias espalhadas na Terra Indígena Paiterey Garah localizada em Rondônia (município de Cacoal) e Mato Grosso (Rondolândia e Aripuanã), possuindo uma área de 247.880 hectares demarcados e homologados conforme Decreto 88.867, de 18 de outubro de 1983 (GTA, 2008) ${ }^{6}$.

\section{Festa e rituais praticados pelos Paiter Suruí}

A cultura Paiterey é riquíssima e apresenta uma grande diversidade de rituais, tais como: o Mapimaí (criação do mundo), o Ngamangaré (roça nova), o Weyxomaré (pintura), o Hoeyateim (festa em que o xamã controla os espíritos da aldeia), o Lawaãwewa (construção de casa nova) e o Ytxaga (pesca com timbó). Alguns rituais de passagem são praticados, como o da Menina Moça, que marca a passagem da infância para a adolescência na primeira menstruação da jovem (ISA, 2012).

É importante destacar que as festas e danças tradicionais sofreram muitas alterações, e muitas vêm, aos poucos, sendo abandonadas devido aos conflitos ideológicos com as novas religiões introduzidas nas comunidades indígenas. A festa ritualística Mapimaí, por exemplo, foi realizada no ano de 2002 depois de 12 anos sem ser realizada e segundo os Suruí, a festa foi retomada em memória à morte de alguns deles. As festas comemoradas (natal, aniversário, datas civis etc.) pela sociedade não indígena foram em grande parte assimiladas pelos Paiterey,

\footnotetext{
${ }^{4}$ Mirindiba (Lafoensia glyptocarpa): Fruta regional da floresta Amazônica

${ }^{5}$ GAMEB PAITER. Disponível em http://gasodaSuruí.blogspot.com/2011/09/paiter-iama.html. Acessado em 13/03/2012).

${ }^{6}$ Grupo de Trabalho Amazônico (GTA). O Fim da Floresta - A Devastação das UC e Terras Indígenas no Estado de Rondônia. Porto Velho, 2008. Disponível em http://stat.correioweb.com.br/cbonline/junho/ofimdafloresta.pdf. Acessado em 13/03/2012.
} 
conforme afirmam a etnia e o Instituto Sócio Ambiental (ISA). A OSCIP Kanindé tem oferecido incentivo e apoio à perpetuação da cultura indígena Suruí ao longo dos anos, principalmente do Mapimaí, com vários registros e filmagens sobre o ritual.

No presente artigo abordamos o ritual do Mapimaí realizado em agosto de 2011, ao qual fomos convidados e participamos durante a semana de representação indígena. Neste artigo se encontram nossas impressões acerca de sua importância para os Paiter Suruí.

\section{O percurso metodológico: vivências e experiências}

Para atingir os objetivos propostos foram utilizados como ferramentas metodológicas o levantamento bibliográfico prévio e posteriormente, in loco, observações empíricas da realidade, entrevistas, gravações e aquisição de imagens através de filmagem e fotografia, as quais registram todas as etapas que compõem o ritual, as quais englobam vários cerimoniais ou passagens na preparação do ritual festivo, que pode levar dias.

As entrevistas foram divididas entre pesquisadores para abranger o maior número possível de entrevistados e de coleta de material. Consistiu principalmente no diálogo com antigas lideranças indígenas que carregam o acervo cultural dos Paiter Suruí e mantem viva sua cultura. Foram entrevistadas também algumas lideranças com idades intermediárias e idades mais jovens que incorporaram outros valores à sua cultura, como forma de adaptação e sobrevivência entre dois mundos, um remoto e ancestral e outro contemporâneo fruto da realidade em que atravessam, porém estes dois mundos se comunicam e as gerações mais recentes seguem os valores, os costumes, as crenças, respeitam a cultura ancestral e são visionários de um novo mundo que devem compreender e se adequar para a própria defesa e sobrevivência.

As entrevistas foram na maioria gravadas para garantir o teor completo das conversas e seus conteúdos transcritos à mão. As lideranças entrevistadas foram fotografadas para manter o acervo, sendo que se usou uma filmadora para registrar todas as etapas e passagens do ritual festivo.

Foi também registrado o teor da conversa entre os Paiter Suruí e alguns não indígenas, como políticos locais, procuradores da república, funcionários da FUNAI, prefeituras, universitários, entre outros que foram convidados a participar de uma roda de diálogos e responder várias perguntas sobre contextos variados no campo da política, no campo social, ambiental e antropológico. Essa condição teve como objetivo encontrar respostas às várias lacunas de questionamentos não muito claros que acontecem no universo Paiterey; em síntese, o ritual festivo possui, principalmente, o escopo de fortalecer a união entre clãs e de encontrar novas estratégias que permitam o exercício da cultura e da cidadania indígena. 


\section{A compreensão do ritual Mapimaí como criação do mundo Paiterey}

O Mapimaí é um dos principais ritos cerimoniais dos Paiterey, cujo contexto traz reconciliação e busca de equilíbrio entre ser humano, cultura e natureza, ao tempo em que se promove a união, mantem alianças entre os clãs e fortalece a cultura. O sentido do Mapimaí é a renovação da energia de criação entre os clãs. Neste cerimonial, os Paiter Suruí procuram responder as questões sobre a origem do mundo, expressar sua identidade e sua forma de organização social. $\mathrm{Na}$ realidade, o Mapimaí é composto de vários ritos de passagem os quais são descritos a seguir:

\section{Metade da mata e metade da roça}

Os Paiterey são formados por clãs que partilham as mesmas regras sociais e que na vida em comunidade se dividem em duas metades, uma ligada ao mato denominada Metare (floresta ou mato) e a outra à roça denominada Íwai (roça). Essas metades são interdependentes, e em sua lógica de organização social as famílias mudam de lado em ciclos anuais, sendo assim, quem é do mato passa a ser da roça e vice-versa. Todos possuem compromissos com o seu lado nos vários tipos de trabalhos possíveis entre caça, roça e confecção de objetos, cada qual com a demanda da roça ou da mata. A oposição entre a mata e a roça organiza o calendário anual dos Paiter. A divisão entre as metades determina vários momentos da vida social, passando pela produção de alimentos, festas e rituais (ISA, 2012).

O Metare, além de ser um lugar de preparação do ritual que fica contido na floresta ou mata, aonde são feitos arcos, flechas, enfeites de pluma ou palha, cocares, tudo isto em meio a conversas, muita diversão ${ }^{7}$ e degustação de comida como carne moqueada, peixe assado, castanha (Bertholletia excelsa), gongo de babaçu (Pachymerus nucleorum) e outras iguarias, é também um local de prática de jogos e excursões. Várias redes são armadas debaixo das árvores para o descanso e concentração.

As waled (mulheres) fazem as peças de cerâmica, os colares, os cestos, fiam e tecem tipoias para carregar os filhos, além de cintos e colares de algodão (Gossypium sp.), tudo com muito urucum (Bixa orellana) e sob orientação de artesões indígenas. Os objetos artesanais produzidos no Metare são destinados às trocas de presentes no final do Mapimaí, onde os membros de uma metade passam para à outra e vice-versa, em meio aos cantos, danças e muita bebida.

A festa ritualística Mapimaí acontece no período de colheita ou no plantio, em que as metades trocam presentes e alimentos. A preparação da festa do

\footnotetext{
${ }^{7}$ Utilizamos a palavra diversão para facilitar o entendimento de seu mundo, mas na realidade trata-se de troca de experiências, de convivência, que é realizada de forma descontraída, ou seja, sem o rigor que é observado na sociedade urbano-industrial.
} 
Mapimaí leva meses, sendo necessária a produção de imensas quantidades de chicha, a bebida fermentada tradicional. Trata-se de dias seguidos de cerimoniais complexos, para que todas as pessoas posam se enfeitar com colares, cocares, plumas e cintos de algodão pintados. No Metare, que está localizado no interior da mata, há mais fartura de caça e pesca e os moquéns estão sempre cheios de carne. O tempo para se dedicarem a estas atividades são maiores (ISA, 2012).

No dia de tomar a bebida da festa um imenso cortejo parte do mato para a aldeia, em cantos e teatro rituais. As waled dos chefes cerimoniais conduzem tochas de fogo, que não podem e nem devem ser apagadas, pois isso significaria não só um sinal de que irão morrer cedo, como também de que o demiurgo, o ser criador da humanidade, Palop ("nosso pai" ou "nosso Deus") se recusa a visitar e proteger a aldeia. A tocha possui o sentido da vida material e espiritual, a qual é um símbolo de grande importância para o modo de vida e para a cultura Paiterey.

No Mapimaí acontece a troca de presentes entre as metades, sendo que os Íwai, grupo da roça ou da comida, são anfitriões. Os Íwai devem prover nas festas a chicha denominada de "iatir", ofertada pelo Deus "Palob" - herói mítico criador de todas as coisas e que protege o território e sua gente. A chicha é uma espécie de bebida fermentada dos Paiterey, feita com milho (Zea sp.) e/ou inhame (Colocasia esculenta (L.) Schott.), cará (Dioscorea alata L.) e que adquire teor alcoólico - sendo um elemento de purificação espiritual.

Os Íwai precisam de roças maiores para suas "oferendas" e devem dedicar mais tempo para colher e cozinhar, já a outra metade, os do Metare, fica na floresta às margens de um igarapé, embora continuem a trabalhar na roça como os outros. Um conjunto de tapiris provisórios (casas) é construído em semicírculo para cada família na clareira eleita para sediar o Metare. O Metare está ligado às andanças, ao prazer das excursões, achados inesperados, aos alimentos subitamente abundantes, sem que seja necessário esperar pelo ritmo das estações e pelo crescimento das plantas, como acontece com a roça (ISA, 2012).

No Mapimaí de 2011 foi realizada a representação do encontro entre as duas metades: os Íwai, anfitrões da festa, e os Metare, a outra metade que vive em clareiras no mato. Antes deste encontro os clãs se separam um dos outros, cada qual no seu espaço. É acesa uma fogueira, carne é assada e redes são armadas (Figura 01, p.09).

Há toda uma preparação para o encontro entre as duas metades, a qual é iniciada com as pinturas corporais à base de jenipapo (Genipa americana) coletado na floresta, bem como a confecção de flautas (Figura 02, p.10) feitas de taboca (Guadua sp.). A preparação e realização do ritual é uma dádiva de Palop, sendo que a responsabilidade das ações não ocorre por vontade individual humana, mas pelo desígnio espiritual, de modo que existem pessoas específicas para determinadas funções dentro do Mapimaí. 


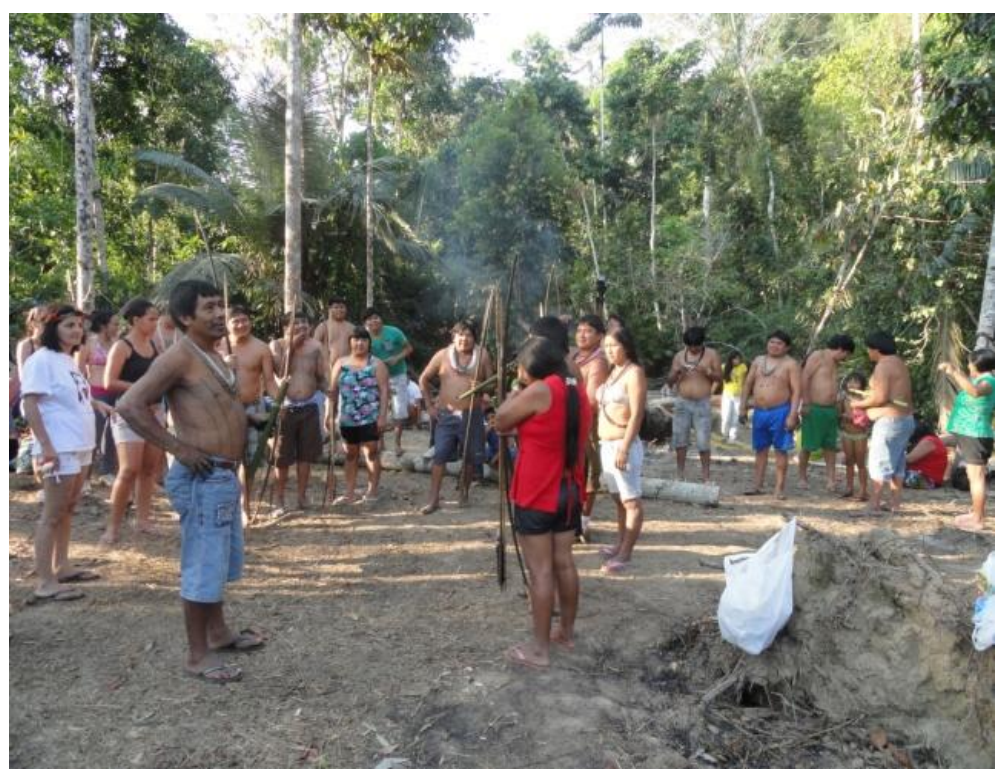

Figura 01 - Preparação dos "Metare" que estão na floresta aguardando o encontro com a outra metade, os Íwai. Aldeia Apoena Meireles, 23.08.2011.

Fonte: MARETTO (2011).

São confeccionados diversos tipos de adornos para enfeitar o corpo, como mantas desfiadas de palha de babaçu (Orbignya martiana B. Rodr.), plumas, chocalhos presos aos pés, cocares, cinto de algodão, arco, flechas etc. Cada clã procura fazer suas pinturas corporais características, ou seja, que representam sua metade exogâmica e que cobrem todo o corpo e inclusive o rosto, em forma de traços que representam o gavião, os peixes e outros animais e frutos da floresta. As flautas são afinadas para produzir um som específico de cada metade.

Ao finalizar todos os preparativos que antecedem ao ritual, os clãs que ocupam o Metare partem em fila ao som de flautas e cantos ao encontro da outra metade, que são os Íwai, que os espera com várias panelas de cerâmica grandes repletas de chicha, a qual foi preparada com antecedência e se encontra em estado avançado de fermentação e com certo grau alcoólico. Neste cortejo da saída do Metare ao Íwai, as waled se seguram na cintura de seus maridos e namorados e seguem em fila (Figura 03, p.11), e quando chegam à aldeia, no local preestabelecido, dançam e cantam em círculo ao som das flautas. 


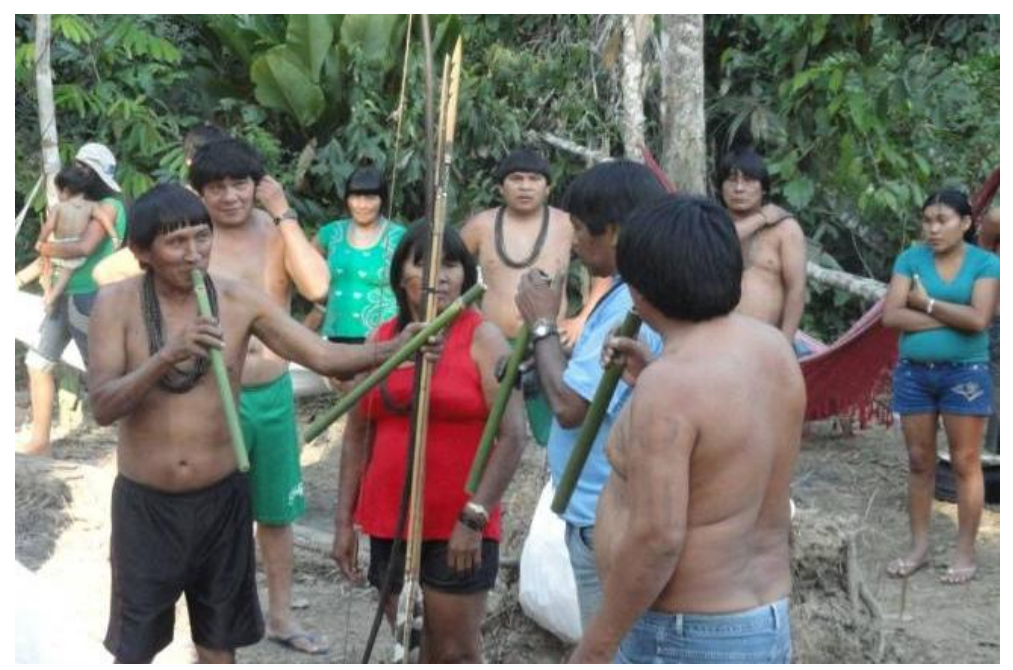

Figura 02 - Preparação e afinação de flautas para a festa do Mapimaí. Aldeia Apoena Meireles, 23.08.2011. Fonte: MARETTO (2011).

Os clãs confrontam-se entre si - como algo lúdico - e desafiam-se em beber chicha até não suportar mais, sempre com cantos e danças ao som de flautas. Os maridos são acompanhados pelas waled, e o mesmo ato se repete com elas, que bebem seguidamente em pequenas panelas de cerâmica que são servidas pelo Íwai. Quando não suportam mais regurgitam tudo o que ingeriram e começam a beber novamente até a completa exaustão. É aí que se dá o desafio. Quando isso ocorre estão purificando o organismo e o espírito, jogando para fora as coisas ruins e quem termina de beber e não tolera mais, perde o desafio.

Segundo entrevista concedida por Arildo Gameb Suruí, os dois chefes que se confrontam fazem várias disputas, por exemplo, aquele que fala menos é "rebaixado". Outro desafio do grupo é beber chicha sem cair. Aquele chefe que cai é derrotado, com isso não é considerado como alguém forte o suficiente, não é uma liderança plena. 


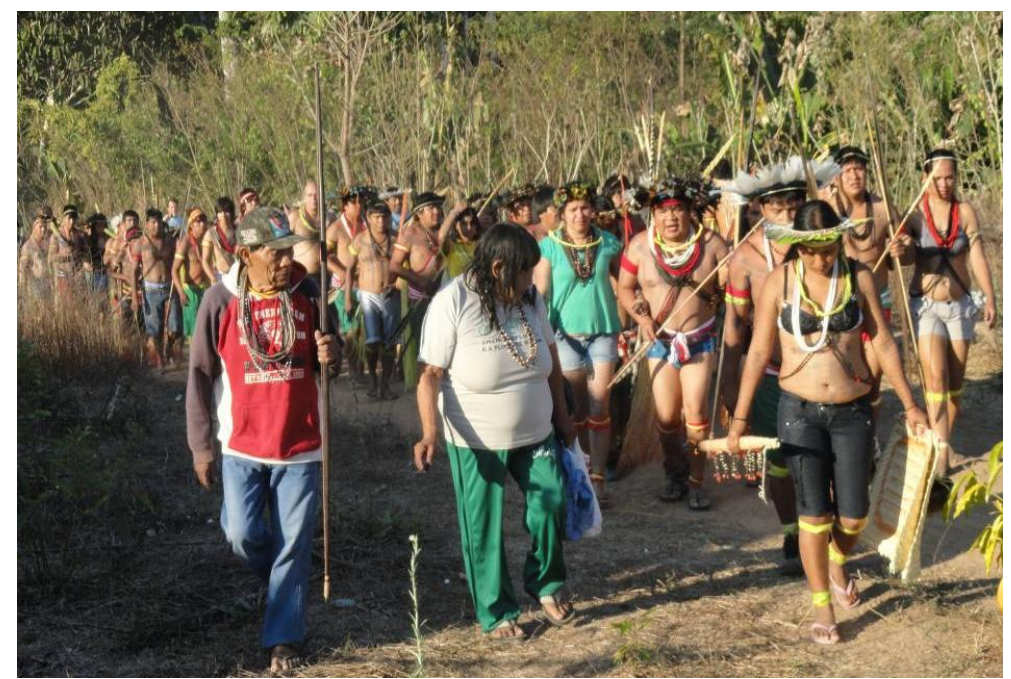

Figura 03 - Caravana se deslocando do Metare para se encontrar com os Íwai, a outra metade, ao som de flautas e muito canto. Aldeia Apoena Meireles, 23.08.2011.

Fonte: MARETTO (2011).

As músicas possuem letras que abordam os símbolos escolhidos. No ritual ocorre também um desafio no canto das músicas, onde aquele que canta mais e não repete as letras leva vantagem, e consequentemente é convidado pelos donos da chicha, os Kaban, a sentar-se no Iamá (trono). Há todo um ritual a ser seguido, em que o dono da chicha convida os representantes de cada clã a sentar-se no tronco de madeira ou trono.

Pela constatação relatada em entrevista por Itabira Suruí, do clã Kaban, a metade Íwai anfitrião do ritual, afirma que apenas três pessoas são escolhidas para tocar flauta e uma pessoa é escolhida para guiar o ritual. Segundo ele, os Paiterey tocam músicas que falam do gavião real, da floresta e da água, anunciam a chegada e encontro das duas metades alegando que estão prontos para o desafio. Os três flautistas puxam as canções e os outros executam músicas que não podem ser repetidas.

Na cosmogonia Paiter Suruí, a flauta simboliza a criação do mundo, isto porque quando Palop criou o mundo, estava tocando flauta, instrumento utilizado no ápice de sua criação, que foi o mundo. A musicalidade só pode ser entendida entre quem está tocando e o espírito. No Mapimaí o instrumento musical serve como uma comunicação entre quem está bebendo a chicha e quem está tocando, 
cujo contexto é a vinculação espiritual dos Paiterey e seu fortalecimento espiritual e cultural frente aos desafios que são colocados em seu cotidiano.

O Mapimaí é o momento que também envolve a confraternização e a afirmação da identidade cultural, pois nele se ampliam os laços de parentesco como condição indispensável de elaboração de estratégias que permitem o vínculo com a territorialidade e a reflexão sobre os destinos do povo. Assim, tem-se além da representação, o estabelecimento de vínculos que remetem à ancestralidade e à necessidade de construir alianças que permitem pensar o território dentro do contexto atual em que vivem.

\section{Iamá}

O Iamá é um tronco de madeira retirado de uma árvore sagrada para os Paiterey. É extraída toda a casca] e posteriormente recoberto com pintura à base de urucum. Nele são pintados peixes e outros animais, que expressam uma caçada e logo depois sentam os líderes, anciões e pessoas consideradas importantes entre os indígenas.

Na concepção cosmogônica dos Paiterey, segundo entrevista de Gasodá Gameb Suruí, o trono é feito para os oy (homens), em especial os líderes, guerreiros e pajés, que o utilizam para sentar-se no pátio da aldeia ou dentro da maloca. É aí que conversam de forma coletiva acompanhados de suas waled e dos seus filhos para decidir e refletir sobre o mundo. O trono é utilizado durante as realizações de rituais como o Mapimaí (Festa da Criação do Mundo) e Hôeyatem (invocação dos bons espíritos através da pajelança para cura dos doentes e proteção contra o mal).

Arildo Gameb Suruí complementa, em entrevista, a argumentação da importância dessa representação para seu povo, ao afirmar que:

O Iamá é um trono em forma de tronco de madeira para recepção das pessoas. Na festa do Mapimaí sentarão o chefe da oferenda e os três líderes por ele convidados. São dois tronos de madeira, um fica no pátio da aldeia e outro dentro da maloca que é o principal e, que só o dono da chicha pode sentar primeiro e depois convida os demais a sentarem. Somente dez minutos, depois de chamados, os convidados podem sentar no trono e começam a cantar. As mulheres não podem olhar para o trono, tem que ir de cabeça baixa.

No ritual de 2011, foram convidados pelo dono da chicha a sentar-se no trono (Figura 4, p.13), os chefes de clã Almir Suruí, Luís Suruí e Marimop Suruî . O terceiro a sentar-se foi acompanhado do segundo chefe. Do meio para o final da festa ritualística os chefes convidados começaram a cantar. Estas etapas se

\footnotetext{
${ }^{8}$ Alguns dias depois da realização do ritual, este grande líder e um dos mais idosos entre os Paiterey teve morte natural - ele deixou um enorme legado de experiências para o seu povo.
} 
realizaram dentro de uma programação cosmogônica a ser cumprida fielmente pelos presentes.

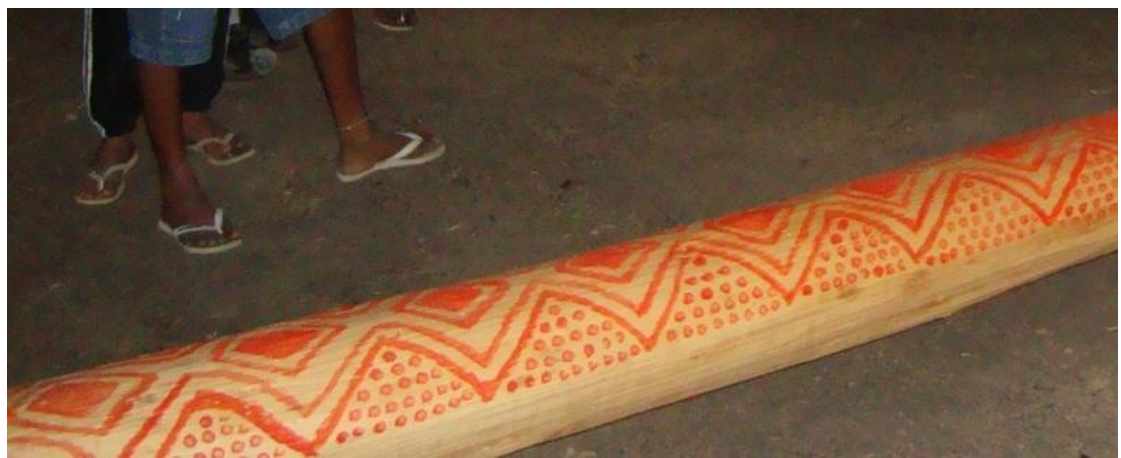

Figura 4 - Iamá, trono ou banco de madeira onde os chefes convidados se sentam no ritual. Fonte: (GAMEB PAITER.

Disponível em http://gasodaSuruí.blogspot.com/2011/09/paiter-iama.html. Acessado em 13/03/2012).

\section{Os adornos}

Os oy se enfeitam com cinturões de algodão pintados de vermelho e branco ou verde e branco, com artesanato de tucumã (Astrocaryum aculeatum) e pena, cocares de penas de pássaros e de couro de onça pintada (Panthera onca). Nos tornozelos, joelhos e braços são amarrados linhas vermelhas confeccionadas de algodão. No tronco do corpo são colocados vários colares de tucumã e algodão, formando um xis, enquanto outros ficam pendurados no pescoço. Os corpos são pintados com jenipapo em listras, circunferências, traçados de diversas formas de modo a representar animais e pássaros. No tornozelo são colocados chocalhos feitos com sementes de castanha, amarrados cordas de algodão cru.

As waled pintam o corpo de acordo com sua condição social: solteira, casada, jovem, criança, idosa. As pinturas representam pássaros e animais da floresta. Usam ainda belos arranjos nos cabelos feitos de penas e cocares. O corpo é envolvido com vários colares de tucumã, de algodão e outras sementes e penas. Nos pulsos e dedos são colocados, respectivamente, pulseiras e anéis de tucumã. Os tornozelos, joelhos e braços recebem linhas de algodão vermelhas semelhantes aos utilizados pelos $o y$.

Alguns oy e waled usam longas palhas, como se fossem véus. As palhas são cozidas, lavadas no igarapé e pintadas na parte de baixo com urucum, ficando uma listra vermelha forte que vai suavizando mais para as pontas. Na parte de cima da cabeça fora colocado um cordão de algodão formando uma espécie de coroa enfeitada com penas e sementes do mato. Os indígenas que usavam estas 
vestimentas não eram mais considerados humanos e sim espíritos invisíveis que causavam certo medo.

Esses adornos são partes integrantes de um corolário de espiritualidade, sendo que cada um desses ornamentos possui suas próprias representações e são utilizados para fins específicos. Cada metade exogâmica possui uma representação própria de cor que está relacionada à formação do clã.

\section{Entrando pela noite}

Ao pôr do sol os Kaban descem até a Metareilá (local de reunião) onde estão os demais clãs (Gameb, Makor e Gamir), seguem cantando em direção a cada clã, na frente encontra-se a waled do chefe do Metare que sempre olha para baixo com respeito, transporta o fogo ${ }^{9}$ da vida, uma espécie de tocha, enquanto seu esposo cuidadosamente protege o fogo para que não se apague. Em seguida vem o chefe dos Kaban com suas esposas, filhos e filhas, genros, noras, netos e netas, sobrinhos e todos os membros do clã. Pedem licença para entrar no Metareilá e, finalmente, os visitantes são convidados a acompanhá-los.

Cada clã segue os anfitriões com reverência e cuidado para que o fogo não se apague. $\mathrm{O}$ chefe dos Kaban puxa um canto que conta a história do povo, e de como eles venceram os invasores. Todos cantam, assim que um cessa de cantar, dá lugar aos demais. São cantadas histórias dos tempos imemoriais, percorrem com a música as referências do contato com a sociedade não indígena e finalmente retratam os dias atuais.

$\mathrm{O}$ cortejo se dirige à maloca. Entra nesta a waled e seu esposo que se senta no Iamá, e os líderes passam em sua frente cumprimentando com seriedade e respeito, em seguida saem da maloca para o pátio onde dançam e cantam, num ritmo às vezes lento, outras vezes mais acelerado. Cada líder, chefe de família, jovens e velhos cantam suas histórias, suas narrativas míticas e seus cotidianos.

Ao cantarem sobre as caçadas, entram na maloca novamente e flecham um cesto colocado no alto que em seu interior contém peixe e tatu, cuja representação se refere aos inimigos do passado e do presente.

Posteriormente todos saem e dançam ora de lado, ora de frente, em batidas fortes com os pés levando o grupo por todo o espaço destinado à apresentação. Incursionam novamente na maloca e o dono da festa começa a distribuir o iatir - bebida fermentada - em enormes vasilhas de cerâmicas (nos tempos atuais há uma mescla de cerâmica, plástico e alumínio). O visitante tem que beber exageradamente até não suportar mais, regurgitar tudo, e logo em seguida bebe novamente.

\footnotetext{
${ }^{9}$ Se no transcurso do caminho a tocha de fogo se apaga significa um prenúncio de que alguém do povo poderá entrar brevemente em óbito, segundo a aquisição cosmogônica dos Paiter Suruí.
} 
Quem deixar de beber perde os presentes que serão ofertados aos que produziram a chicha. A única forma de não beber muito é dividi-lo com parentes do mesmo clã ou com parentes da esposa. $\mathrm{O}$ fato de dividirem a bebida implica no oferecimento de nova vasilha com a iguaria ritualística.

Num primeiro momento, a pessoa que não está acostumada ao ato tem uma sensação bem desconfortável, porém com o transcorrer do ritual entra num estado de leve a moderada embriaguez, e motivado pela história de vida daquele povo, que dança e canta suas glórias, derrotas, vitórias e forma de ver o mundo, passa a compreender seus códigos e seu modo de vida.

Passados estes momentos, todos são convidados a andar por cima do Iamá, para testar se ainda têm equilíbrio, e inicia-se uma disputa entre os clãs, vencendo aquele que ao final tiver maior número de pessoas que não caíram. É interessante notar que não existe demonstração de desprezo pelos derrotados, porém todos comemoram com a mesma alegria, numa demonstração de que tudo é uma grande disputa ritualística e fortalecimento dos laços de amizade. $\mathrm{O}$ ritual festivo segue noite adentro, com cada participante cantando suas histórias.

\section{O casamento}

As waled são de grande valor para os Paiter Suruí, em virtude de firmarem vínculos de parentesco entre os clãs. Itabira, chefe dos Kaban, toma a decisão de fortalecer seus laços com os Gamep e oferece sua filha Ivaneide para o Labiway esaga (cacique maior) Almir.

Itabira manda buscar sua filha no Metare, e junto com sua esposa Noemi preparam-na para o casamento. Suas roupas são tiradas e em seus tornozelos, joelhos, pulsos e braços são colocadas pulseiras vermelhas, feitas de algodão e pintadas de urucum. Seu corpo inteiro é pintado com jenipapo e os desenhos representam sua condição de futura esposa. Na cabeça da moça colocam um cocar com penas de araras. Os adornos do corpo, cada um com suas representações, oferecem vários significados tais como: proteção, sorte, saúde, felicidade, entre outras questões relacionadas à espiritualidade, ao tempo em que se consubstanciam como "marcadores territoriais" (ALMEIDA SILVA, 2010).

Com a noiva pronta, descem todos em cortejo rumo ao Metare para ofertála ao noivo, que até o momento não sabia que iria casar. Ao chegarem ao local conversam com o noivo e seu pai Marimop, e reforçam a ideia do quanto é importante a aliança entre Gamep e Kaban e que a partir desse momento, aceitando o casamento, passam à condição de parentes mais próximos. Desse modo, todos saem em cortejo rumo à maloca cantando músicas que se referem àquele momento sagrado. 


\section{A troca e a reciprocidade: “o pagamento" pela boa festa}

No dia seguinte todos estão prontos para iniciar as trocas de presentes, não sendo permitido ao clã Kaban pegar nada, já que eles ofereceram o ritual festivo. A esposa de Nema - chefe do ritual - inicia a troca de presentes. Ela retira de cada participante dos outros clãs o que lhe agrada, roupas, adornos, tudo que possa transportar; depois todos começam a trocar objetos entre os participantes pegando o que lhes interessa. Não é permitido recusar a entrega do objeto, pois o simbolismo deste ato indicaria uma espécie de pagamento pelo trabalho realizado para preparar o evento.

Esse ato integrante dos Paiter Suruí remete-nos ao enunciado de Mauss (1968-1969 [1931a, b], 1997 [1950], 2003) quando aborda a questão da troca e reciprocidade, ou seja, relacionando este ato à estrutura fundamental de parentesco e filiação, o que conduz à percepção de sua territorialidade.

\section{A preparação da roça}

Pela manhã todos se dirigem ao lugar escolhido pelo chefe da aldeia para preparar a roça comunitária. Todos os oy pegam facões, foices, roçadeiras, machados, e realizam a derrubada e a limpeza do local. Estes assobiam, outros puxam cantos relacionados ao plantio. Cantam e prosseguem realizando a limpeza do terreno e preparam-no para o plantio de milho e cará.

\section{A distribuição de alimentos}

Enquanto um grupo prepara a roça, outro sai para caçar. Os caçadores chegam ao início da tarde, com queixadas (Tayassu pecari), macacos, mutum (Crax globulosa), caititu (Pecari tajacu) e entregam estes produtos da caça ao anfitrião. Os oy preparam o moquém (jirau em que se assa carne) e as waled cozinham em enormes panelas de barro parte dos animais caçados.

À noite o chão é recoberto com esteiras, onde o anfitrião distribui a carne em proporções de acordo com o papel de cada pessoa dentro da organização social Paiterey. Só os oy recebem carne, que passam às suas esposas, que repassam aos filhos e filhas. Os convidados recebem pedaços individuais.

Quando todos se encontram alimentados o Mapimaí se encerra, então ocorre a despedida entre os parentes e assim regressam às suas aldeias.

\section{A floresta}


Entendemos a floresta como uma das representações mais importantes para a cultura dos Paiterey. Devido a isso reproduzimos alguns dos diálogos pertinentes estabelecidos quando de nosso trabalho de campo em 2011.

Pela experiência cosmogônica, Itabira Suruí explica em entrevista que:

Existem espíritos nas florestas e nos rios, eles se manifestam em sonhos e convidam as pessoas. A floresta é igual à gente mesmo, tem espíritos que defende a floresta e que defende os rios. Tem espírito do bem e do mal. Os espíritos da floresta se chamam "Lokapoyo" e dos rios se chamam "Moaneycrio". O Pajé é escolhido pelo espírito e a pessoa tem que merecer. Para a cultura Suruí há um Deus maior que criou a natureza, a floresta e os rios. Há um Deus que sempre está paralelo e junto. Se maltratar a floresta o espírito castiga o povo. A floresta preserva as nascentes, rios e dá alimento. O espírito "Lokapoyo" vive no mato, caça e castiga quem derruba a floresta, mas também pode curar. É um espírito bom e mau ao mesmo tempo. [...] que quem é dono do macaco é o gavião real, quem é dono do porco é a onça e quem é dono da cobra é o mutum. Seu pai era pajé. [...] Em 1987 começou a exploração de madeira na Terra Indígena Sete de Setembro. Os espíritos da floresta ficaram bravos. Esta exploração de madeira foi autorizada na época pelo Senador Romero Juca e houve incentivo na época através da própria Fundação Nacional do Índio (FUNAI) para os indígenas Suruí venderem madeira [...].

A liderança João Lawad Suruí concorda com Itabira Suruí ao argumentar em entrevista que:

A floresta tem muita importância para seu povo. Hoje os Suruí estão resgatando o que perderam da floresta vendendo madeira e estão buscando o valor da floresta nos tempos atuais [...]. Há espíritos na floresta que ajudam seu povo. O pajé ajuda na cura de doenças e ajuda a preservar a água [...]. Há uma relação muito forte da festa do Mapimaí com a floresta, rios e animais. $O$ gavião real é um símbolo forte e só alguns líderes usam a pena do gavião real para fazer flecha. [...]. Desde 2008 presido o Instituto Florestal Yaner que faz feira cultural vendendo produtos da cultura Suruí. A sede fica na linha 11 na aldeia Joaquim Suruí (Nome dado ao seu falecido pai). O instituto surgiu depois da morte de seu pai que foi assassinado por madeireiros da região. A ideia da criação do instituto foi para sobreviver e ganhar dinheiro sem ter que vender madeira e desmatar a floresta. Foi uma maneira encontrada em memória de seu pai que era contra a venda de madeira. Além de meu pai, 12 caciques já foram assassinados por causa da venda de madeira. A feira da cultura ensina os jovens a aprenderem a arte de fazer artesanato, caçar e aprender a cultura de um modo geral. Uma vez por mês é feito 
uma confraternização e os produtos são colocados à venda. Os nãos índios também participam da feira comprando produtos [...]. Hoje os Suruí estão desenvolvendo um projeto de carbono $(R E D D+)$. Todos os clãs foram convidados e participam mesmo aqueles que vendem madeira. O projeto de carbono é uma forma de valorizar a floresta e unir os clãs resgatando a cultura e ao mesmo tempo trazendo recursos econômicos para o povo. $O$ projeto está sendo implantado em várias aldeias. Inicialmente foi construído um viveiro de produção de mudas na Aldeia Lapetanha e posteriormente foi elaborado projetos de enriquecimento florestal em área de capoeira e projeto de reflorestamento em áreas degradadas.

A importância da preservação e conservação também é destacada no diálogo-entrevista de Romero Mopidapenen Paiter Suruí, da Associação GarahPameh do clã Kaban:

Em 2008 foi dado início ao projeto de reflorestamento $e$ enriquecimento florestal na Aldeia Apoena Meireles. A ideia do projeto é aproveitar as áreas degradadas e áreas de capoeiras abandonadas para plantar espécies nativas de interesse econômico e cultural como: mogno, frutíferas, açaí, tucumã etc. Sou um dos articuladores políticos das cinco associações indígenas que existem na Terra Indígena Sete de Setembro e que o plantio de enriquecimento florestal de sua aldeia abrangem 15 alqueires ou aproximadamente 37,50 hectares de área. [...] A floresta é importante por preservar os rios, os peixes, os animais, os alimentos naturais, remédios, etc. Precisamos manter a floresta para viver no mundo atual mantendo a identidade cultural, fazendo ritual e festas e, para não depender totalmente de alimento e remédios da cultura não índia.

Desse modo pode-se constatar que a floresta é uma representação coletiva, cuja importância cosmogônica e na sociodiversidade reflete o modo de vida dos Paiterey, conforme afirma em entrevista Arildo Gameb Suruí:

A floresta é importante para os povos indígenas porque é o espaço de sobrevivência de onde as famílias tiram seu sustento, recebem energia, para cultuar seus rituais e crenças. É importante porque foi criada por Deus, tanto os seres vegetais como os animais. Deus foi classificando as coisas e formando os vegetais e animais. Alguns animais como a anta, jabuti, gavião, urubu, dentre outros, eram gente há tempos atrás. Deus foi chamando estas pessoas e foi determinando que você seja um animal da floresta com determinada função. $O$ nambu, por exemplo, toda manhã vai assoviar e cantar como um relógio que indica o amanhecer. $O$ nambu também é alimento e suas penas são utilizadas em artesanatos. [...] Os indígenas Suruí antigos dizem que o ser (gente) tem uma relação harmônica com a floresta e devem ter respeito por esta, caso contrário, os espíritos castigam quem a maltrata. Estes espíritos só aparecem para as pessoas que tem o coração de respeito, que tem o dom $e$ 
afinidade com a floresta e com toda sua biodiversidade que esta possui. Quem não respeita a floresta corre o risco de não voltar porque o espírito "Lokapoyo" e outros fazem a pessoa se perder. $O$ espírito "Lokapoyo" tem várias serpentes no corpo e carrapatos que pegam as pessoas e levam no topo de uma pedra que amolece e engole a pessoa até a altura do peito. A pessoa pede socorro, e logo aparece outro espírito "Lokapoyo" que castiga ainda mais a pessoa. Teve uma pessoa, que segundo o pajé testemunhou, foi libertada após ficar um dia e meio presa. Após a libertação um destes espíritos levou a pessoa com velocidade a aldeia. [...].

Todas as questões anteriormente mencionadas indicam a preocupação dos Paiterey em salvaguardar a cultura, o território, perpassam o seu âmbito interno e produzem reflexões de alerta para a sociedade, isto porque entendem que o problema ambiental atinge a todos indistintamente no Planeta.

Diante dos argumentos expostos se percebe que a sustentabilidade permeia várias áreas do conhecimento humano e está relacionada ao meio econômico, político, social, cultural, ecológico e ambiental equilibrado. A sustentabilidade, deve ser seguida como um modelo que venha a satisfazer as necessidades das gerações atuais, sem comprometer a capacidade das gerações futuras de satisfazer suas próprias necessidades (SACHS, 1993).

\section{Considerações Finais}

A análise do presente artigo sobre o ritual Mapimaí oferece resumidamente importantes lições tais como: a) entender que as representações de mundo têm o sentido claro de valorização e respeito às distintas culturas e apreensão de sua importância como marcas indeléveis que se situam como possibilidade de obtermos, ainda que utopicamente, um planeta melhor; b) a criação do mundo e os valores presentes em cada cultura demonstram que não possuímos a dimensão necessária para entender a relevância do conhecimento tradicionais destas culturas; c) os valores atribuídos ao ambiente e modo de vida são condições "sine qua non" para compreender os símbolos e as representações simbólicas como possibilidade de buscar o ser humano há tanto tempo esquecido dentro de nós.

No tocante à floresta, no contexto antropológico, tem um valor inestimável para a cultura indígena, sendo fonte dos recursos naturais que lhes garante o alimento, abrigo, remédios e principalmente porque é o local onde permanecem vivos os espíritos de seu mundo cosmogônico que interagem com seus habitantes, mantendo a cultura viva. No contexto econômico tem importância por lhes apresentar recursos que auxiliam na sobrevivência cotidiana nesta época contemporânea competitiva; do ponto de vista ecológico possui inestimável relevância por assegurar serviços ambientais fundamentais à sobrevivência da vida. 
Assim, observa-se que o modo de vida, percepções e apreensões dos Paiter Suruí encontram-se alicerçados numa vasta experiência em seu espaço de ação, o qual confere a territorialidade, a identidade étnica que se interligam intrinsecamente os seus valores fundamentais, sendo a espiritualidade e a herança cosmogônica - como se constata no ritual do Mapimaí, entre outras manifestações - sustentáculos da cultura Paiterey.

A valoração das experiências vividas pelos Paiterey no seu espaço de ação, como vimos, é plena de sentidos, representações e significados que nos possibilita melhorar a compreensão da diversidade humana, que no caso dos indígenas e populações tradicionais se manifesta na interconexão íntima com o ambiente. $\mathrm{O}$ ambiente é aqui entendido como um conjunto holístico que incorpora valores espirituais, imateriais e materiais, sendo, portanto, condição indispensável para a realização de outras leituras com distintas perspectivas de construções e vivências de mundo.

\section{Referencial}

ALMEIDA SILVA, Adnilson de. Territorialidades e identidade dos coletivos Kawahib da Terra Indígena Uru-Eu-Wau-Wau em Rondônia: "Orevaki Are" (reencontro) dos "marcadores territoriais". Tese de doutorado. UFPR - Curitiba, 2010. $301 \mathrm{p}$.

INSTITUTO SÓCIO AMBIENTAL (ISA), 2012. Disponível em http://pib.socioambiental.org/pt/povo/Suruí-paiter/print. Acessado em 10/09/2012)

MAUSS, Marcel. Essais de Sociologie. Paris: Éditions de Minuit (tomos 1 e 2 de Oeuvres).(1968-1969 [1931a]).

. Oeuvres. Paris: Editions de Minuit, vol. 3. (1968-1969 [1931b]).

. Essai sur le don: forme et raison de l'échange dans les sociétés archaïques, (1997 [1950]).In__. Sociologie et anthropologie. Paris: PUF - (ed. original: Année Sociologique, seconde série, tome 1, Paris, 1923-1924).

. Sociologia e Antropologia. São Paulo: Cosac \& Naify, 2003.

SACHS, Ignacy. Caminhos para o desenvolvimento sustentável. Paula Yone Stroh (Org.). 3. Ed. Rio de Janeiro: Editora Garamond, 2008. 96 p. 


\section{Documentos/Internet}

Gameb Paiter - Disponível em http://gasodaSuruí.blogspot.com/2011/09/paiteriama.html. Acessado em 13/03/2012.

Grupo de Trabalho Amazônico (GTA). O Fim da Floresta - A Devastação das UC e Terras Indígenas no Estado de Rondônia. Porto Velho, 2008. Disponível em http://stat.correioweb.com.br/cbonline/junho/ofimdafloresta.pdf. Acessado em 13/03/2012.

Instituto Sócio Ambiental (ISA). Disponível em http://pib.socioambiental.org/pt/povo/Suruí-paiter/print. Acessado em 10/09/2012).

Luis Carlos Maretto

Mestre em Geografia pela Universidade Federal de Rondônia. Pesquisador do Grupo de Estudos e Pesquisas Modos de Vidas e Culturas Amazônicas GEPCULTURA.

Campus - BR 364, Km 9,5 CEP: 76801-059 - Porto Velho - RO.

E-mail: 1cmaretto@gmail.com

Almir Narayamoga Suruí

Graduado em Ciências Biológicas pela Pontifícia Universidade Católica de Goiás e Doutor Honoris Causa em Geografia pela Universidade Federal de Rondônia. Atualmente é consultor da Associação de Defesa Etnoambiental e professor do Programa de Pós-Graduação em Geografia da Universidade Federal de Rondônia.

E-mail: almirsurui@gmail.com

Adnilson de Almeida Silva

Pós-Doutor em Geografia na Universidade Estadual de Ponta Grossa - UEPG, Doutor em Geografia pela Universidade Federal do Paraná, mestre e graduado em Geografia pela Universidade Federal de Rondônia. Doutor em Geografia UFPR (2010). Atualmente é professor do Departamento de Geografia e do PPGG/UNIR.

Campus - BR 364, Km 9,5 CEP: 76801-059 - Porto Velho - RO.

E-mail: adnilsonn@gmail.com

Recebido para publicação em novembro de 2013

Aprovado para publicação em abril de 2014 